Research Article

\title{
Investigation of Concrete Base-Roadbed Surface Contact Variation-Induced Vibration Characteristics of Vehicle-Slab Track-Subgrade System considering Fluid-Solid Interaction
}

\author{
Kai-Wen Liu $\mathbb{D}^{1,2,3}$ Fei Yue, ${ }^{1}$ Qian Su, ${ }^{1,2}$ Bao Liu, ${ }^{4}$ and Pengfei Zhou ${ }^{5}$ \\ ${ }^{1}$ School of Civil Engineering, Southwest Jiaotong University, Chengdu, Sichuan 610031, China \\ ${ }^{2}$ Key Laboratory of High-Speed Railway Engineering, Ministry of Education, Southwest Jiaotong University, Chengdu, \\ Sichuan 610031, China \\ ${ }^{3}$ State Key Laboratory for GeoMechanics and Deep Underground Engineering, China University of Mining \& \\ Technology (Beijing), Beijing 100083, China \\ ${ }^{4}$ China Railway Design Corporation, Tianjin 300000, China \\ ${ }^{5}$ Tangshan Institute, Southwest Jiaotong University, Tangshan, Hebei 063000, China
}

Correspondence should be addressed to Kai-Wen Liu; kaiwenliu@swjtu.edu.cn

Received 19 January 2019; Accepted 14 April 2019; Published 8 July 2019

Academic Editor: Pedro A. Costa

Copyright (C) 2019 Kai-Wen Liu et al. This is an open access article distributed under the Creative Commons Attribution License, which permits unrestricted use, distribution, and reproduction in any medium, provided the original work is properly cited.

The excessive pumping of fines in saturated roadbed surface layer, which is induced by the fluid-solid interaction under dynamic loads from high-speed train, is a special form of high-speed railway subgrade defect reported recently. This can deteriorate the interface between nonballasted track structure bottom layer and roadbed surface layer and therefore lead to associated contact variation with the moving of trains. According to the dynamic Biot's equations known as $u$ - $p$ formulation and the vehicle-track coupling dynamics theory, a vertical vehicle-slab track-subgrade coupling vibration model is developed to investigate the aforementioned contact variation-induced dynamic behavior of the whole system considering the fluid-solid interaction. Dynamic measurements from a field case study are adopted to verify the computation model proposed. Based on the numerical model validated, the effects of three contact variation statuses (continuous contact, vibrating contact, and contact loss) on dynamic responses of track subsystem and subgrade subsystem, such as dynamic pore-water pressure, vertical accelerations, and dynamic displacements both in time and frequency domains, are investigated. Also, a sensitivity analysis involving rail speeds and lengths of contact loss zone is performed, and the critical length of contact loss zone is suggested.

\section{Introduction}

Prefabricated slab track, which possesses the advantages of higher permanent stability and lower maintenance [1], has hitherto been considerably applied in nonballasted track systems of high-speed railway. To achieve better operating comfort and safety, high smoothness and stability of nonballasted track are strictly required. Also, the importance is increasingly attached to keep the subgrade structure in an intact condition.

Main numerical formulations modeling of the dynamic response of railway structure under moving train loads involves the finite element method and the semianalytical method [2-9]. For example, rail pad properties [10] on dynamic performance of railway track were analyzed numerically. The wheel-rail dynamic interaction was investigated based on the theory of vehicle-track coupled dynamics with a modified excitation model of rail spalling failure proposed [11]. In order to optimize slab railway tracks, a comprehensive analysis of the shakedown limit load of nonballasted railway tracks was carried out using an efficient numerical model [12].

In addition to numerical research studies, several field case studies and experimental tests have been reported. For instance, a site investigation focusing on the dynamic behavior of railway tracks at a culvert transition zone is presented [13], and the track dynamic responses of operational trains were monitored [14, 15]. Based on field 
measurements, the excitation of railway-induced ground vibration [16] and the vibration characteristics of underground structures [17] were comprehensively evaluated. Furthermore, laboratory tests were also made to investigate the dynamic responses of track system subjected to transient loads [18] or the vibration behavior of the slab tracksubgrade with mud pumping under cyclic dynamic loading of high-speed train [19].

Local defects (e.g., rail joints, switches, and turnouts) have been considered as one of the main sources of railwayinduced ground vibration $[20,21]$. Due to the combined effects of dynamic train loading, temperature, and other environmental factors such as water, diseases like cracks and voids can be induced inside track structures. It has been found that the vibration responses of the track system can be adversely affected by the contact damage disease underneath track slab induced from the deteriorated cement-emulsified asphalt mortar (CA mortar).

Liu et al. [22] developed a vehicle-track vertical coupling model to study the influence of contact loss on the dynamic properties of vehicle and track subsystems at different train speeds, and the results were experimentally validated. With the same model, Shi [23] analyzed the effect of slab track defects, such as failure of fasteners, subgrade uneven settlement, and contact loss induced by deteriorated CA mortar, on dynamic performances of the slab track system. In addition, Xiang et al. [24] investigated the effect of the suspension of track slab caused by the degradation of CA mortar, such as invalidation, cracking, embrittlement, and cataclasm, on vibration responses of slab track and found that the accelerations and displacements were greatly increased compared to the normal condition of CA mortar.

To overcome the issues studied above, Ren et al. [25] proposed criteria for repairing damages of CA mortar for prefabricated framework-type slab track. The criteria were then applied to a 3D FEM of slab track verified by a field test. Also, a very recent paper of Chen et al. [26] studied the effects of high temperature-induced initial upwarp at the interface between track slab and concrete base on the stability of the CRTS II slab track by FEM and concluded that an initial upwarp with a span of $6.5 \mathrm{~m}$ and a rise of $15 \mathrm{~mm}$ should be avoided to ensure the stability of the CRTS II slab track.

Practically, the interface damage disease does not play an exclusive part in the track system, which also exists in the tracksubgrade system. During the operation of high-speed railways, the roadbed (grain structure), particularly at expansion joints of concrete bases with cracked waterproof materials, exposed to frequent intense rainfalls and groundwater-level variations can change significantly from the condition of optimum water contents of soils to the saturated states due to nonfunctional drainage conditions. When the roadbed surface layer gets saturated, the hydromechanical coupling effect under cyclic dynamic train loads may lead to excessive pumping of fines [27], thereby deteriorating the interface between concrete base and roadbed surface (Figure 1). Consequently, the concrete base is likely not in continuous contact with roadbed surface in some local areas where a certain content of fine particles is washed out, thus affecting the dynamic smoothness of rail and vibration performances of the track system. The literature review shows that existing investigations are mainly confined to the contact loss underneath track slab, and to what extent the contact variation underneath concrete base can affect the vibration responses of track structures is seldom addressed particularly considering the fluid-solid interaction effect.

The aim of this paper is to explore the effect of contact variation between the concrete base and roadbed surface on vibration characteristics of vehicle-slab track-subgrade system considering the fluid-solid interaction effect. Based on the vehicle-track coupling dynamics theory and the theory of fluid dynamics in porous medium, a vertical vehicle-slab track-subgrade coupling vibration model capable of describing the contact variation between concrete base and roadbed surface under high-speed train load is developed with the FEM code COMSOL Multiphysics. Also, it is validated by measured data from a filed case study published by the authors' research group previously. The contact variation-induced dynamic responses of vehicletrack system under different contact statuses (continuous contact, vibrating contact, and contact loss) are discussed, and the critical value of contact loss zone is suggested.

\section{Vertical Vehicle-Track-Subgrade Coupling Model}

The vehicle-track-subgrade vertical coupling system of highspeed railway studied herein consists of three parts: (i) the top structure (train subsystem); (ii) the medium structure (nonballasted track subsystem); and (iii) the bottom structure (subgrade subsystem). Based on the vehicle-track rail system coupling dynamics theory proposed by Zhai et al. [28], the structure of train subsystem can be simplified as a car body, two bogies, and four wheelsets; the nonballasted track subsystem refers to rail, fastener structure, track slab, cement-emulsified asphalt (CA) mortar, and concrete base; the subgrade subsystem involves the roadbed (surface layer and bottom layer) and subgrade body, as shown in Figure 2. The fundamental formulation and methodology of the numerical model developed are briefly described in the following sections.

2.1. Vibration Equations for Vehicle Subsystem. The train is modeled as an assembly of aforementioned rigid bodies with 10 degrees of freedom describing for 7 vertical displacements and 3 rotations [29], interconnected by springs and dampers [30]. The mass of the car, bogies, and wheels as well as the longitudinal rotation inertia of car and bogies are included. The governing equations for the train subsystem may be expressed as follows:

$$
M_{u} \ddot{a}_{u}+C_{u} \dot{a}_{u}+K_{u} a_{u}=Q_{u}
$$

where

$$
\mathbf{M}_{\mathbf{u}}=\operatorname{diag}\left\{\begin{array}{llllllllll}
M_{\mathrm{c}} & J_{\mathrm{c}} & M_{\mathrm{t}} & M_{\mathrm{t}} & J_{\mathrm{t}} & J_{\mathrm{t}} & M_{\mathrm{w} 1} & M_{\mathrm{w} 2} & M_{\mathrm{w} 3} & M_{\mathrm{w} 4}
\end{array}\right\},
$$

where $M_{\mathrm{c}}$ and $J_{\mathrm{c}}$ are mass and rolling moment of inertia for the rigid body of the car, respectively; $M_{\mathrm{t}}$ and $J_{\mathrm{t}}$ are mass and rolling moment of inertia for bogies respectively; and $M_{\mathrm{w} i}$ is the mass of $i$ th wheel. 


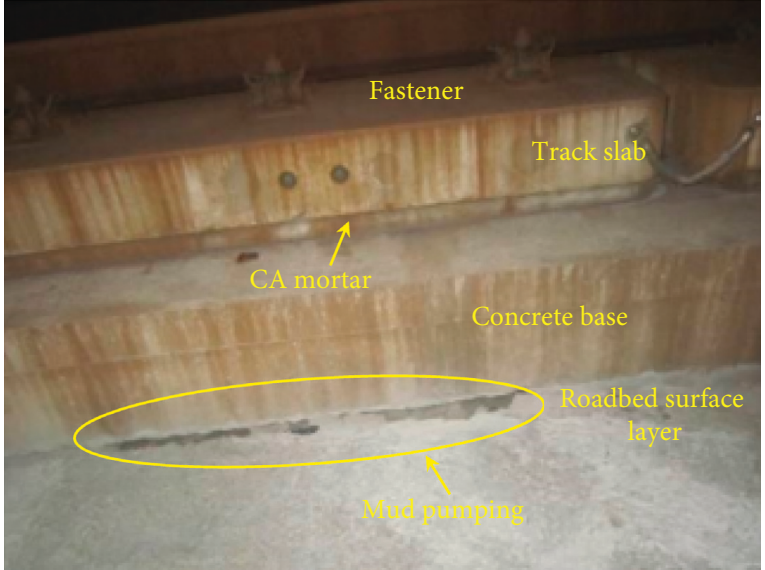

(a)



(b)

FIGURE 1: Mud pumping and associated contact loss of nonballasted track in a high-speed railway: (a) mud pumping and (b) an enlarged view of the contact loss between the concrete base and the roadbed surface.

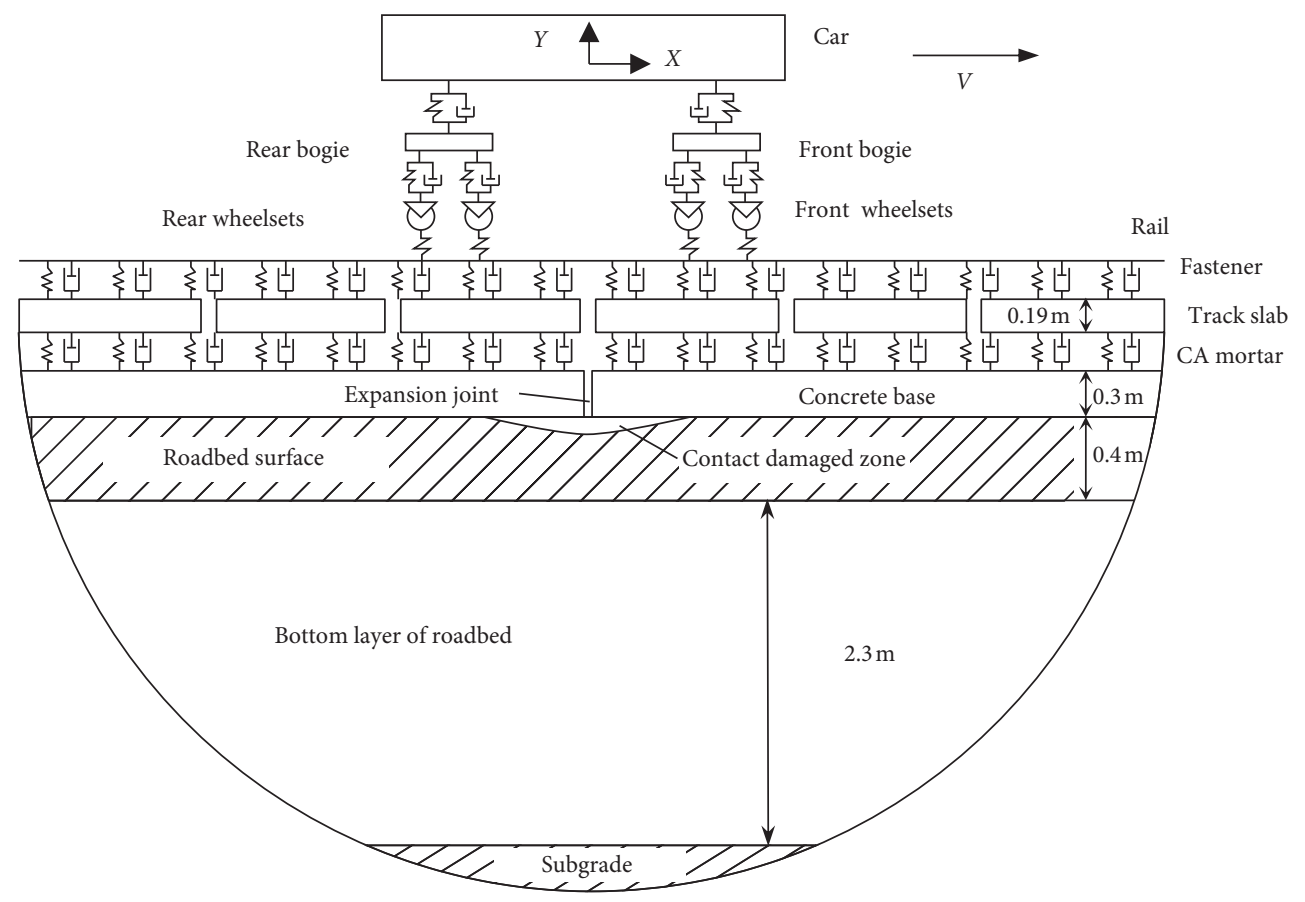

Figure 2: Key components of vehicle-track-subgrade vertical coupling vibration model.

$$
\mathbf{a}_{\mathbf{u}}=\left\{\begin{array}{llllllllll}
v_{\mathrm{c}} & \varphi_{\mathrm{c}} & v_{\mathrm{t} 1} & v_{\mathrm{t} 2} & \varphi_{1} & \varphi_{2} & v_{\mathrm{w} 1} & v_{\mathrm{w} 2} & v_{\mathrm{w} 3} & v_{\mathrm{w} 4}
\end{array}\right\}^{\mathrm{T}},
$$

where $v_{\mathrm{c}}$ and $\varphi_{\mathrm{c}}$ are the vertical displacement and pitch angle of the car body, respectively; $\left(v_{\mathrm{t} 1}, \varphi_{1}\right)$ and $\left(v_{\mathrm{t} 2}, \varphi_{2}\right)$ are the vertical displacement and pitch angle of the front and rear bogies, respectively; and $v_{\mathrm{w} i}$ is the vertical displacement of the $i$ th wheel.

$$
\mathbf{Q}_{\mathbf{u}}=\left\{\begin{array}{llllllllll}
-M_{\mathrm{c}} \boldsymbol{g} & 0 & -M_{\mathrm{t}} \boldsymbol{g} & -M_{\mathrm{t}} \boldsymbol{g} & 0 & 0 & P_{1} & P_{2} & P_{3} & P_{4}
\end{array}\right\}^{\mathrm{T}} .
$$

Detailed equations of the damping matrix $C_{u}$ and the stiffness matrix $K_{\mathrm{u}}$ can be found in [30]. The basic parameters of the vehicle simulated are listed in Table 1.
TABLE 1: Basic parameters of vehicle simulated.

\begin{tabular}{lc}
\hline Parameters & Value \\
\hline Car body mass $M_{\mathrm{c}}$ & $40,000 \mathrm{~kg}$ \\
Bogie mass $M_{\mathrm{t}}$ & $3200 \mathrm{~kg}$ \\
Axle mass $M_{\mathrm{a}}$ & $2400 \mathrm{~kg}$ \\
Secondary suspension stiffness $K_{\mathrm{s}}$ & $0.8 \mathrm{MN} / \mathrm{m}$ \\
Secondary suspension damping $C_{\mathrm{s}}$ & $120 \mathrm{kN} \cdot \mathrm{s} / \mathrm{m}$ \\
Primary suspension stiffness $K_{\mathrm{p}}$ & $2.08 \mathrm{MN} / \mathrm{m}$ \\
Primary suspension damping $C_{\mathrm{p}}$ & $100 \mathrm{kN} \cdot \mathrm{s} / \mathrm{m}$ \\
Fixed wheelbase $2 l_{1}$ & $2.5 \mathrm{~m}$ \\
Distance between bogie pivot centers $2 l_{2}$ & $17.375 \mathrm{~m}$ \\
Stiffness of wheel-rail contact $K_{\mathrm{h}}$ & $1.325 \times 10^{3} \mathrm{MN} / \mathrm{m}$ \\
Axle load $P$ & $140 \mathrm{kN}$
\end{tabular}


2.2. Vibration Equations for Nonballasted Subsystem. In the track subsystem, the rail is assumed as a Euler-Bernoulli beam discretely supported on the concrete slab by springs and dampers [31]. The governing equation for the rail beam can be described by

$$
\begin{aligned}
& E_{\mathrm{r}} I_{\mathrm{r}} \frac{\partial^{4} w_{\mathrm{r}}}{\partial x^{4}}+m_{\mathrm{r}} \frac{\partial^{2} w_{\mathrm{r}}}{\partial t^{2}} \\
& +c_{\mathrm{r}}\left(\frac{\partial w_{\mathrm{r}}}{\partial t}-\frac{\partial w_{\mathrm{s}}}{\partial t}\right)+k_{\mathrm{r}}\left(w_{\mathrm{r}}-w_{\mathrm{s}}\right)=-F(t) \delta(x-V t),
\end{aligned}
$$

where $E_{\mathrm{r}} I_{\mathrm{r}}$ is the flexural stiffness of the rail beam; $w_{\mathrm{r}}$ and $w_{\mathrm{s}}$ are deflection magnitudes of the rail and concrete slab, respectively; $m_{\mathrm{r}}$ is the mass of rail per unit length of the track; $c_{\mathrm{r}}$ and $k_{\mathrm{r}}$ are dashpot damping and spring stiffness per unit length of the track, respectively, resulting from the rail pad and fastening; $F(t)$ is the wheel-axle contact force; and $\delta(x-V t)$ is the Dirac delta function and $V$ is the moving velocity of the train.

The concrete slab and concrete base are treated as elastic continuum and their governing equation can be written as

$$
\sigma_{i j, j}-\rho \ddot{u}_{i}=0 \text {, }
$$

where $\sigma_{i j, j}$ is the stress tensor; $\rho$ is the mass density; and $u_{i}$ is the displacement vector. They are connected by springs with stiffness per unit length of the track $k_{\mathrm{t}}$ from CA mortar and dashpots with damping coefficient per unit length of the track $c_{\mathrm{t}}$ from CA mortar. The related parameters of the nonballasted track model simulated are listed in Table 2.

The calculation of the contact force between the wheel and the rail is described by the nonlinear Hertz contact theory. A train is assumed to move at a constant speed in the positive direction. The contact force between the wheel and rail may be expressed as

$$
F_{\mathrm{c}}= \begin{cases}K_{\mathrm{h}}\left|w_{\mathrm{r}}-w_{w}\right|^{3 / 2}, & \left(w_{\mathrm{r}}-w_{\mathrm{w}}\right)<0, \\ 0, & \left(w_{\mathrm{r}}-w_{\mathrm{w}}\right) \geq 0,\end{cases}
$$

where $F_{\mathrm{c}}$ and $K_{\mathrm{h}}$ are the Hertz contact force and spring constant, respectively, and $w_{\mathrm{r}}$, and $w_{\mathrm{w}}$ are deflections of the rail at a contact point and wheel displacement in contact with the rail, respectively.

2.3. Dynamic Equations for Subgrade Subsystem. The subgrade subsystem is a multilayer structure (see Figure 2). Owing to the drainage system of nonballasted track and the specific mechanical properties of graded gravel adopted in the roadbed surface layer, the roadbed surface can be immersed by water and get saturated with the cracked waterproof materials in expansion joint of concrete base [32]. The roadbed surface layer is accordingly modeled as a twophase saturated porous medium, whereas the others (bottom layer of roadbed and subgrade body) are considered as single-phase elastic soil.

Based on the dynamic Biot's equation known as $u-p$ formulation proposed by Zienkiewicz and Shiomi [33], the dynamic responses of saturated porous media in terms of two variables (the displacement of the solid phase, $u$, and
TABle 2: Parameters of slab track simulated.

\begin{tabular}{lc}
\hline Parameters & Value \\
\hline Mass of rail beam $M_{\mathrm{r}}$ & $60 \mathrm{~kg} / \mathrm{m}$ \\
Flexural stiffness of rail beam $E_{\mathrm{r}} I_{\mathrm{r}}$ & $6756 \mathrm{kN} \cdot \mathrm{m}^{2}$ \\
Elastic modulus of track slab $E_{\mathrm{b}}$ & $36000 \mathrm{MPa}$ \\
Thickness of track slab & $0.19 \mathrm{~m}$ \\
Rail pad stiffness $k_{\mathrm{r}}$ & $60 \mathrm{MN} \cdot \mathrm{s} / \mathrm{m}^{2}$ \\
Rail pad damping $c_{\mathrm{r}}$ & $47.7 \mathrm{kN} / \mathrm{m}^{2}$ \\
CA mortar stiffness $k_{\mathrm{t}}$ & $900 \mathrm{MN} / \mathrm{m}^{2}$ \\
CA mortar damping $c_{\mathrm{t}}$ & $83 \mathrm{kN} \cdot \mathrm{s} / \mathrm{m}^{2}$ \\
Elastic modulus of concrete base $E_{\mathrm{b}}$ & $34000 \mathrm{MPa}$ \\
Density of concrete base $\rho_{\mathrm{b}}$ & $2500 \mathrm{~kg} / \mathrm{m}^{3}$ \\
Poisson's ratio of concrete base & 0.2 \\
Thickness of concrete base & $0.3 \mathrm{~m}$ \\
\hline
\end{tabular}

pore-water pressure, $p$ ) neglecting the acceleration of pore water under dynamic loading can be described through the following governing equations:

$$
\begin{aligned}
\sigma_{i j, j}^{\prime}-\alpha \delta_{i j} p_{, j} & =\rho \ddot{u}_{i}, \\
\alpha \dot{\varepsilon}_{i i}-\left(\frac{k}{\gamma_{\mathrm{w}}}\right) p_{i i}+\left(\frac{n}{K_{\mathrm{f}}}\right) \dot{p} & =0, \\
\sigma_{i j}^{\prime} & =2 \mu_{\mathrm{s}} \varepsilon_{i j}+\lambda_{\mathrm{s}} \varepsilon_{k k} \delta_{i j}, \\
\rho & =n \rho_{\mathrm{f}}+(1-n) \rho_{\mathrm{s}},
\end{aligned}
$$

where $\sigma_{i j}^{\prime}$ represents the effective stress tensor of the solid phase; $u_{i}$ denotes the displacement vector of the solid phase; $p$ is the pore-water pressure; $\alpha$ is Biot's coefficient; $\delta_{i j}$ is the Kronecker delta; $\varepsilon_{i j}$ is the strain component of the solid matrix; $k$ represents the permeability; $\gamma_{\mathrm{w}}$ is the unit of pore water and $K_{\mathrm{f}}$ is the pore fluid bulk modulus; $\mu_{\mathrm{s}}$ and $\lambda_{\mathrm{s}}$ are lame constants of the solid phase; $\rho$ is the mixture mass density; $\rho_{\mathrm{f}}$ is the fluid density; $\rho_{\mathrm{s}}$ is the solid density; and $n$ is the porosity. The related mechanical and hydraulic parameters of subgrade soils are tabulated in Table 3.

2.4. Other Information. The hydraulic conductivity of wellgraded gravel recommended in the design code of highspeed railway is generally between $10^{-3} \mathrm{~m} / \mathrm{s}$ and $10^{-5} \mathrm{~m} / \mathrm{s}$. Based on field observations, roadbed surface where the mud pumping occurs often has a relatively high content of graded gravel fines. Therefore, the $10^{-5} \mathrm{~m} / \mathrm{s}$ order of magnitude is selected as the value of hydraulic conductivity of roadbed surface layer in the dynamic hydromechanical coupling calculation. Generally, the surface water and rainfall flow into roadbed surface layer through nonfunctional expansion joints due to aging and cracking, and therefore it is considered as drainage boundary.

\section{Model Validation}

A field case study conducted by the authors' research group [34] on Shanghai-Nanjing intercity railway line was adopted to verify the proposed computational scheme. In this field test, the piezoelectric accelerometer and displacement 
TABle 3: Parameters of subgrade soil simulated.

\begin{tabular}{lccc}
\hline Parameters & Roadbed surface layer & Roadbed bottom layer & Subgrade body \\
\hline Thickness $(\mathrm{m})$ & 0.4 & 2.3 & 1.2 \\
Elastic modulus $E(\mathrm{MPa})$ & 200 & 150 & 0.3 \\
Poisson's ratio $v$ & 0.25 & - & 0.35 \\
Solid density $\rho_{\mathrm{ss}}\left(\mathrm{kg} / \mathrm{m}^{3}\right)$ & 2300 & - & - \\
Liquid density $\rho_{l}\left(\mathrm{~kg} / \mathrm{m}^{3}\right)$ & 1000 & 1700 & - \\
Soil density $\rho\left(\mathrm{kg} / \mathrm{m}^{3}\right)$ & 2040 & - & - \\
Porosity $n$ & 0.2500 \\
Compressibility parameter $\alpha$ & 0.95 & - & - \\
Fluid viscosity $\eta(\mathrm{Pa} \cdot \mathrm{s})$ & 0.001 & - & - \\
Permeability $k(\mathrm{~m} / \mathrm{s})$ & $10^{-5}$ & - \\
\hline
\end{tabular}

gauges were installed at the top of the concrete base and roadbed surface near an expansion joint between concrete bases. In this test, data acquisition and processing were performed mainly based on the running of a high-speed train at a test speed of $247 \mathrm{~km} / \mathrm{h}$, which is operated for a passenger train, with a marshalling mode of 2 trailer cars and 6 motor cars.

The calculated acceleration-time curve of the concrete base at the concerned location shows noticeable 16 group peak amplitudes corresponding to the acceleration responses of the concrete base at the moment of 8 cars with 16 bogies passing, which were induced by the effects superimposed by 2 wheelsets of the single bogie. Thus, the load characteristics of the single axle pair of either front or rear bogie are not obvious (see Figure 3(a)). The calculated acceleration of the roadbed surface at the concerned location indicates that peak amplitudes with loading and unloading processes are not as evident as those on the concrete base, particularly at the moment of bogies except for the first and last bogie passing, which is likely due to the system damping effect and the geometry effect of the vibration wave transmitted to the top surface of the roadbed (see Figure 3(b)). The peak amplitudes were mainly caused by the superimposed effect of 4 wheelset axle load of the rear bogie and the front bogie between two adjacent cars. The calculated acceleration-time curves from both the concrete base and the roadbed surface are generally consistent with measured ones.

\section{Three Different Contact Statuses}

The progressive mud pumping on the roadbed surface layer induced from the coupling action of water and cyclic loading deteriorates the interface between concrete base and roadbed surface, which may lead to voids in some areas particularly close to expansion joints. According to field investigations, the contact variation between the concrete base and the roadbed surface may be presented as three stages, i.e., the continuous contact, vibrating contact, and contact loss, respectively, corresponding to no contact damage, incipient contact damage, and full contact damage. Based on site observations and simulation results, it is found that the elliptical-shaped form can be selected as the most suitable form to describe the contact loss zone realistically, which is governed by the

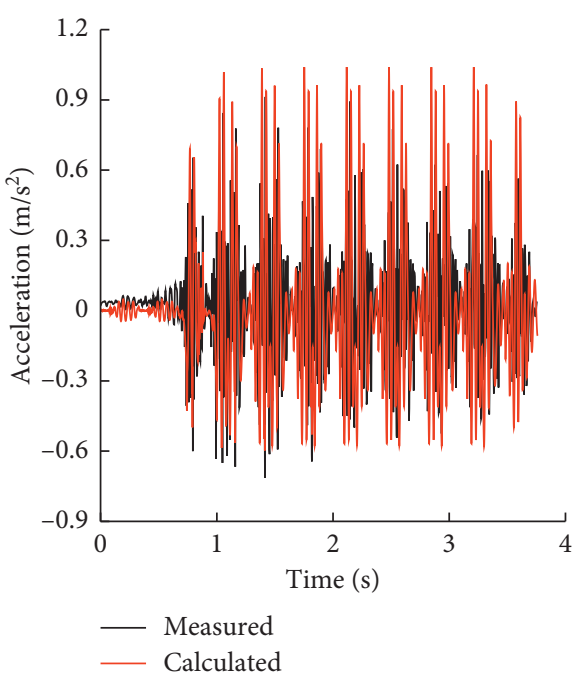

(a)

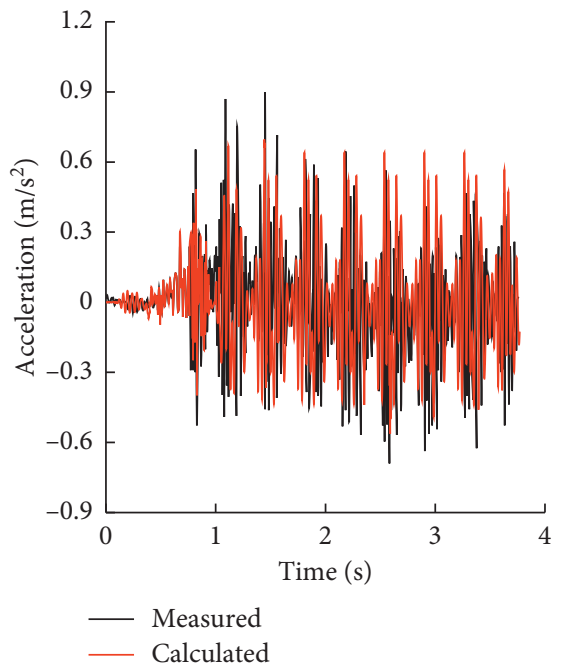

(b)

Figure 3: Calculated and measured acceleration-time curves: (a) the concrete base surface and (b) the roadbed surface.

displacement function and spring-damping element variation. As is shown in Figure $4, H$ and $L$ are, respectively, the depth and length of contact damaged area. Following discussion is all based on the numerical model just validated in the previous section. 


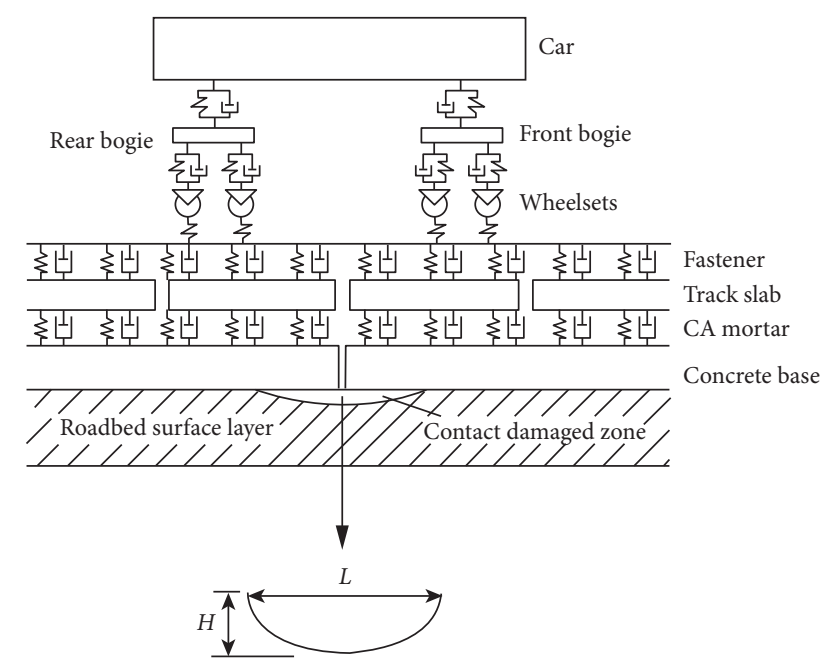

Figure 4: Elliptical-shaped form of contact damaged zone.

Figure 5 shows the dynamic stress distribution of the roadbed surface under such three kinds of contact statuses at the moment of the rear bogie passing with a rail speed of $250 \mathrm{~km} / \mathrm{h}$. The length of the contact damaged zone of both vibrating contact and contact loss considered was 10 spans of fastener spacing $(0.625 \mathrm{~m})$, and the depth of the contact damaged area was $0.16 \mathrm{~mm}$ and $1 \mathrm{~mm}$, respectively. The longitudinal distribution of the dynamic stress is remarkably different when the rear bogie travels through the damaged area. The dynamic stress under the state of continuous contact smoothly distributes along the longitudinal direction, while under the other contact statuses, the dynamic stress has great changes between seriously large stress concentration and zero in a certain range in the contact damaged area highlighted with green lines. Further, there are four contact positions (two corners and two contact points with vibration within the contact damaged zone) for the case in vibrating contact but only two contact positions (two corners of contact damaged zone) for the case with contact loss. The maximum dynamic stress of each contact status (continuous contact, vibrating contact, and contact loss) is $13 \mathrm{kPa}, 21.7 \mathrm{kPa}$, and $65.6 \mathrm{kPa}$, respectively. It is clear that the dynamic stress at the corner of contact loss zone exceeds five times of that in the normal contact condition, which is the most detrimental to the train operation safety.

Figure 6 illustrates the dynamic pore-water pressure distribution in different contact statuses for the same case as in dynamic stress distribution. Compared with these three cases, the distribution of the dynamic pore-water pressure outside the contact damaged zone is basically the same while the three cases show significant difference in the contact damaged zone. For the case of continuous contact, the distribution of dynamic pore-water pressure is pretty smooth longitudinally as does the dynamic stress, except for a sudden decrease at the drainage boundary (the expansion joint). For the case of contact loss, when the rear bogie passes through the contact damaged zone, the dynamic pore-water pressure increases sharply at the two corners of the contact damaged zone and reduces to almost zero inside the contact loss zone, which is consistent with the finding of dynamic stress. For the

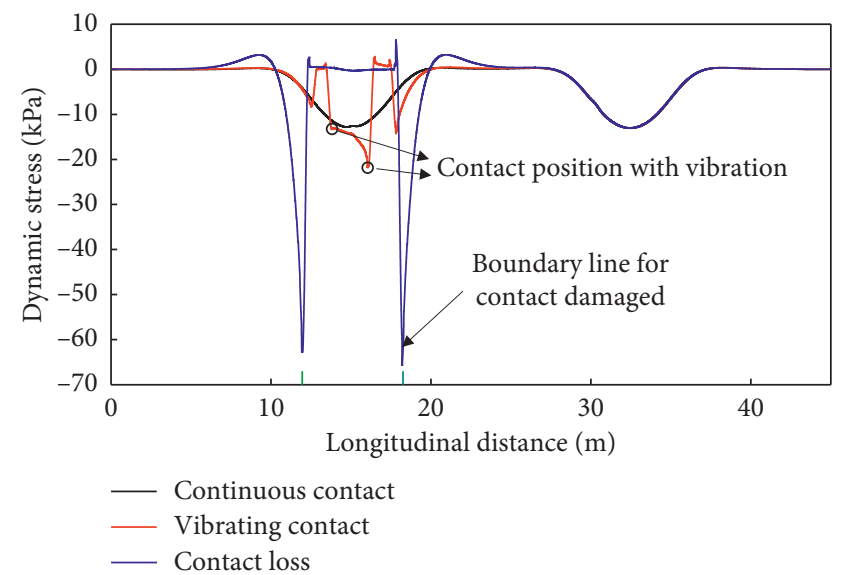

FIgURE 5: Dynamic stress distribution longitudinally on the roadbed surface in different contact states.



FIgURE 6: Dynamic pore-water pressure distribution of roadbed surface longitudinally in different contact states.

case of vibrating contact, the dynamic pore-water pressure shows a steep increase at two vibrating contact positions and then decreases to almost zero at the expansion joint. This indicates that the transient impact and stress concentration occur at the corner of the contact damaged zone and vibrating contact positions, and the dynamic behavior in these three cases is worth being further discussed.

\section{Vibration Characteristic for the State of Vibrating Contact}

5.1. Time-Frequency Analysis of Vehicle-Track System. It can be observed from Figure 7(a) that both cases clearly show four interaction points corresponding to 4 wheelset axle loading at the moments of the front and rear bogies passing the expansion joint. Also, the dynamic rail displacement in the middle of contact damaged zone in the state of vibrating contact is slightly larger than that at the same location in the case of continuous contact. Vibrating contact positions between the concrete base and the roadbed surface, which can be considered as extremely short narrow strips, dynamically change with the vehicle movement, leading to the short interval deformation 


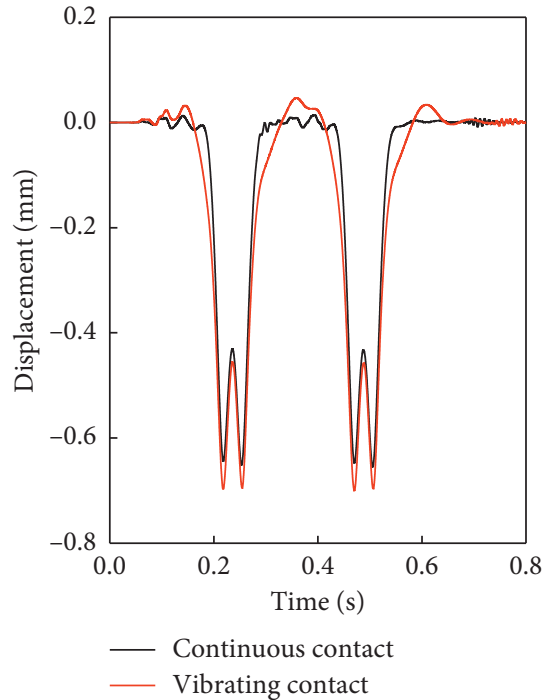

(a)

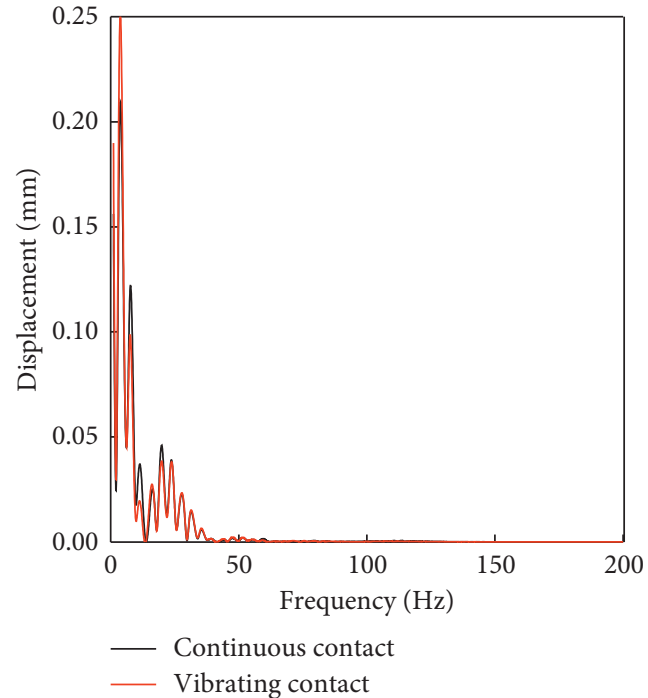

(b)

FIGURE 7: Dynamic displacements of rail in the states of continuous contact and vibrating contact: (a) time domain and (b) frequency domain.

uncoordinated. Before reaching the critical status of contact loss, the dynamic shortwave irregularity excitation induced from time-varying contact stiffness between the concrete base and the roadbed surface has been largely dissipated by the spring-damping system made up of the fasteners and CA mortar, with little effect to the rail vibration, which may be explained for this very slight difference of rail displacements between two cases. As depicted in Figure 7(b), the dominant excitation frequency of both conditions mainly ranges below $40 \mathrm{~Hz}$ with a main excitation frequency being approximately $4 \mathrm{~Hz}$, which is consistent to the excitation frequency of the center-center spacing $(17.375 \mathrm{~m})$ between the front and the rear bogie of a car. According to the comparison, the rail vibration caused by the transient impact in the state of vibrating contact marginally enlarges the vibration response at the fundamental excitation frequency.

For the case of continuous contact, there are only 2 peak amplitudes of dynamic displacements corresponding to 2 bogies of a car, which clearly indicates the superposition of two wheelsets of the same bogie (see Figure 8(a)). This is consistent with the measurement in the field shown before. A similar finding applies to the case in vibration contact although this superposition is not as strong as that in continuous contact but much noticeable than that for the rail displacements in the same case (see Figure 7(a)). Also, due to the effects of dashpot damping from fasteners and CA mortar, the vibration effect on the concrete base is effectively attenuated, with the maximum dynamic displacement being smaller than that of rail directly sustaining the wheelset axle loading. As the front wheel approaches the contact damaged area, the depth of contact damaged zone is filled by the relative distance of the concrete base and the roadbed surface, resulting in a sudden change of the contact status from being loss to being contact. Under the cyclic action of four wheels in the calculation time, the stress concentration caused by the transient impact excites the excess acceleration in vibrating contact positions within the contact damaged area as shown in Figure 8(b).
5.2. Time-Frequency Analysis of Roadbed Surface. The acceleration curves on the roadbed surface at the expansion joint (in the middle of contact damaged area) in the states of continuous contact and vibrating contact are plotted in Figure 9. For the case of vibrating contact, it can be clearly seen from Figure 9(a) that the number of the acceleration amplitudes is equivalent to that of the wheelsets as well as the vibrating contact positions. For the case of continuous contact, the acceleration almost varies evenly with time when the wheelsets pass through the same zone, with the amplitude being $0.22 \mathrm{~m} / \mathrm{s}^{2}$, while for the case of vibrating contact, the acceleration increases sharply in an extremely short time when the transient impact occurs at the vibrating contact position on the roadbed surface, with an amplitude of acceleration being approximately 7 times as that in continuous contact, which demonstrates that the vibration response on the roadbed surface is significantly magnified by an abrupt change of interface interaction at vibrating contact locations. As shown in Figure 9(b), the dominant frequency of acceleration distributed in the case of continuous contact mainly ranges below $40 \mathrm{~Hz}$ with a main excitation frequency of $20 \mathrm{~Hz}$. In comparison, the main excitation frequency of acceleration for the case of vibrating contact is $23 \mathrm{~Hz}$ but with a much wider dominant frequency range exceeding $150 \mathrm{~Hz}$. It may be concluded that the high frequency induced from the aforementioned transient impact enlarges the vibration response of the roadbed surface layer in spite of being the similar main excitation frequency.

\section{Vibration Characteristic for the State of Contact Loss}

6.1. Vibration Responses of Vehicle-Track System. Figure 10 shows the acceleration of the car body for the cases of full contact loss with a depth of contact loss zone $(H=1 \mathrm{~mm})$ and different typical lengths of contact loss zone ( $L=3$ spans, 7 spans, and 10 spans) with a comparison case of continuous 


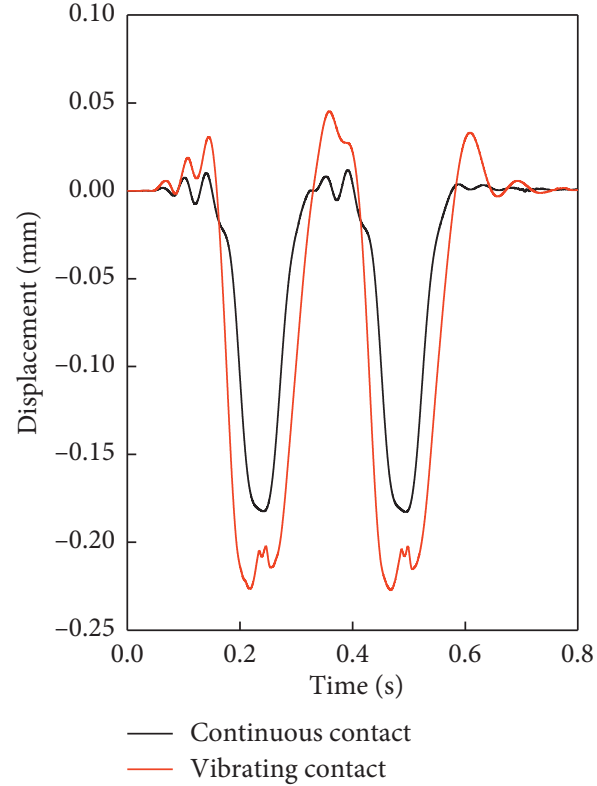

(a)

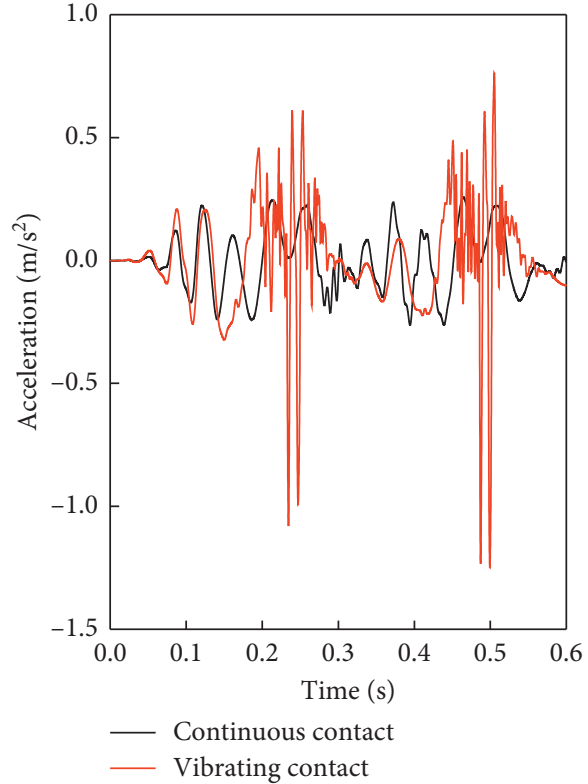

(b)

FIGURE 8: Dynamic displacement and acceleration of the concrete base in the states of continuous contact and vibrating contact: (a) displacement and (b) acceleration.

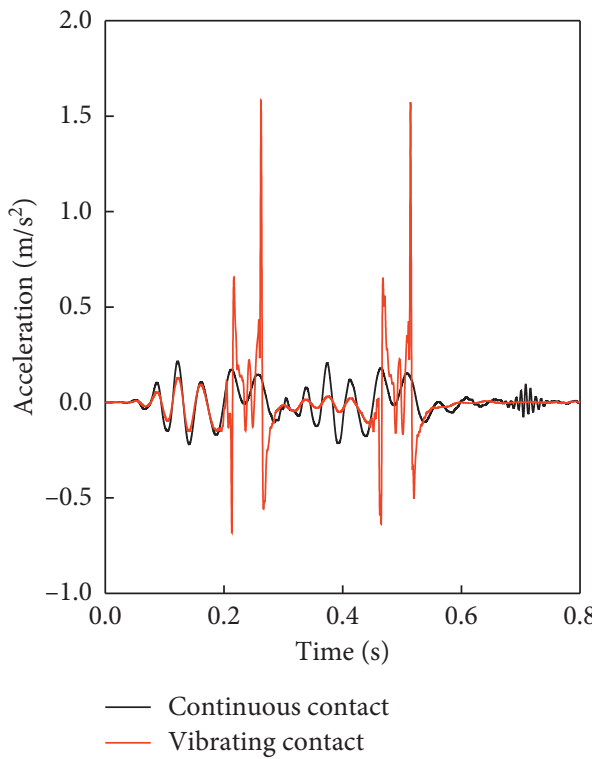

(a)

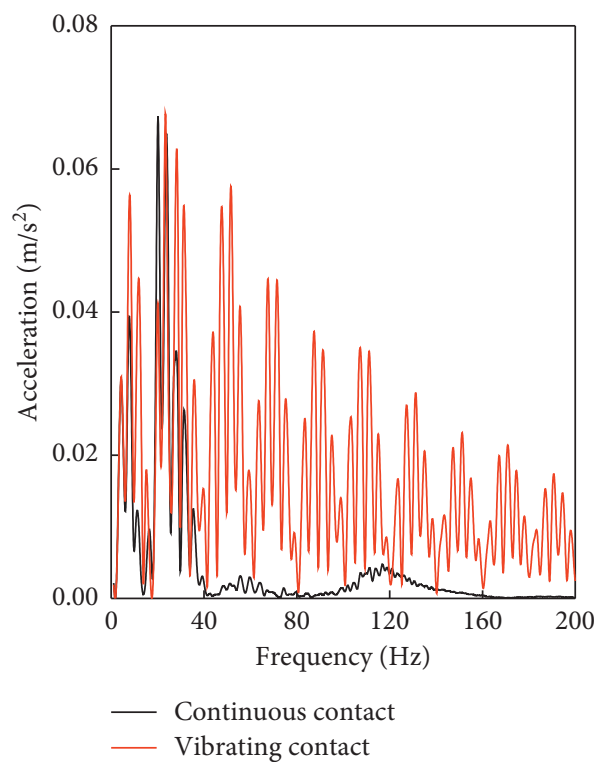

(b)

Figure 9: Acceleration curves on the roadbed surface in the states of continuous contact and vibrating contact: (a) time domain and (b) frequency domain.

contact $(H=0 \mathrm{~mm} ; L=0$ span $)$ at a rail speed of $250 \mathrm{~km} / \mathrm{h}$, where the middle of the contact damaged area is selected as the observation point. The vehicle acceleration varies with the length of the contact loss zone to some extent when the wheelsets pass through the contact loss area (see Figure 10(a)). The main reason for this is that the uneven deformation generated in the contact loss zone due to its irregular shape triggers some irregularity excitation to the upper track structure. As the length of the contact loss zone increases, greater influences are exerted to the vehicle acceleration. Despite the influence of the contact loss length, the total difference in the acceleration between the contact loss with 10 spans length and the continuous contact is less than $0.05 \mathrm{~m} / \mathrm{s}^{2}$, and the dominant frequencies of the acceleration are almost coincided as shown in Figure 10(b), which are likely owing to the attenuation effects of the damping from the CA mortar and the fastener as well as the primary and secondary suspension of the vehicle. Therefore, it may be concluded that the vehicle acceleration variations are not governed by the length of contact loss. 


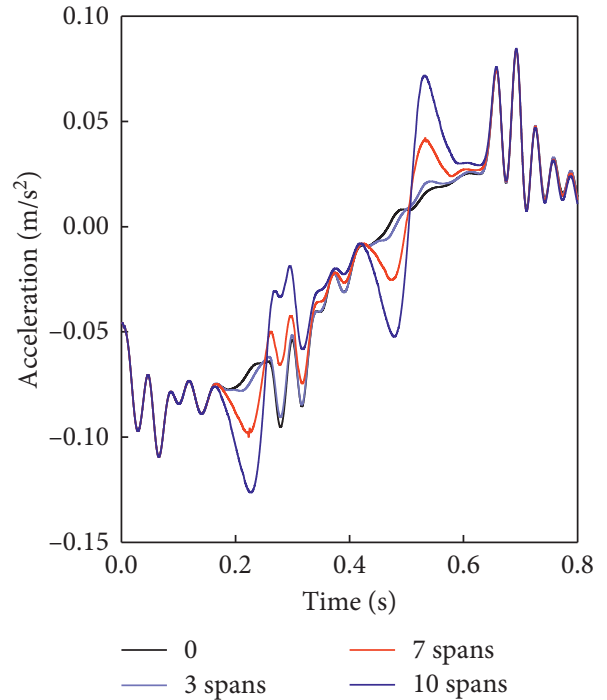

(a)

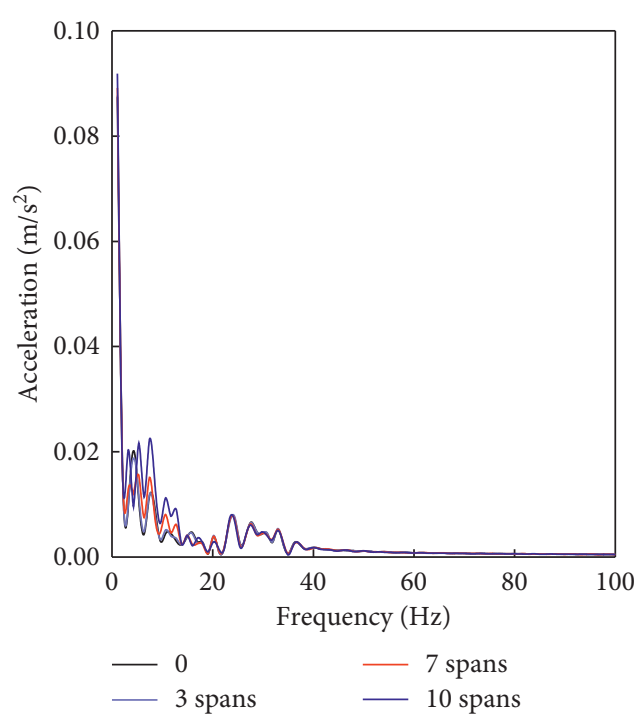

(b)

FIgURE 10: Vehicle acceleration with different lengths of contact loss zone: (a) time domain and (b) frequency domain.

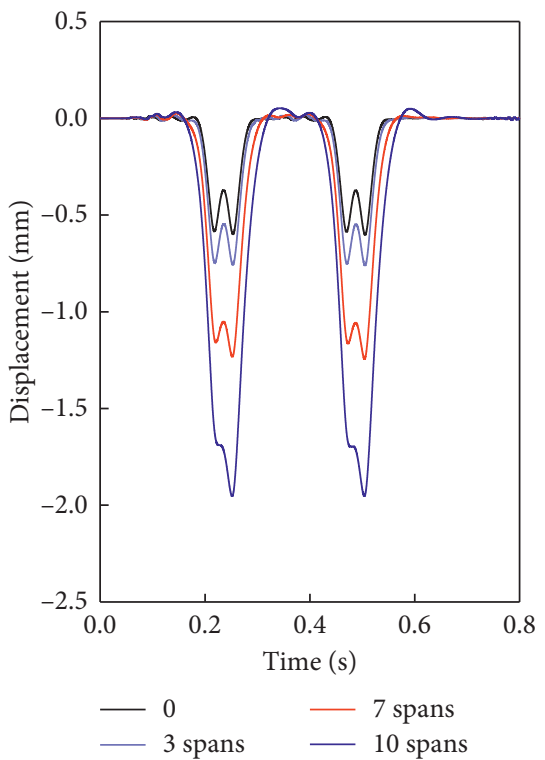

(a)

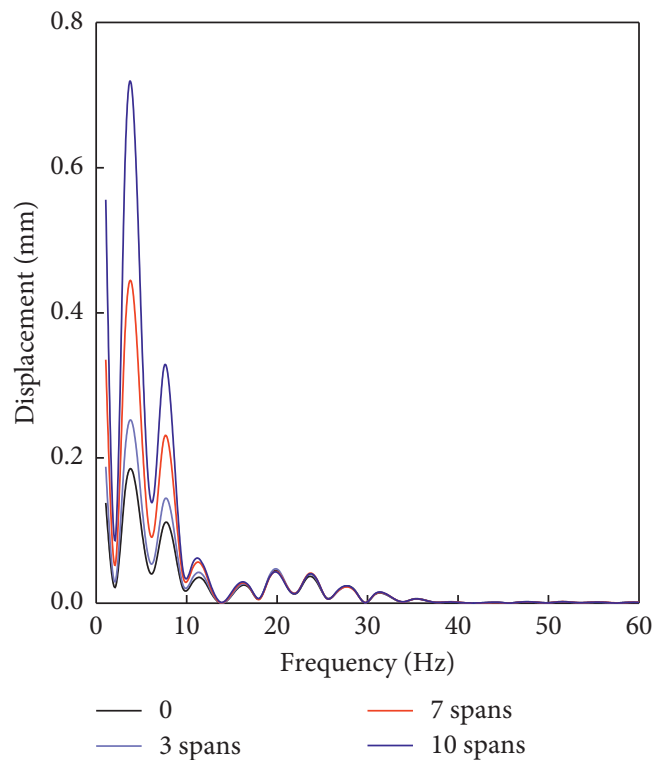

(b)

FIGURE 11: Rail displacements with different lengths of contact loss zone: (a) time domain and (b) frequency domain.

As shown in Figure 11(a), when the length of contact loss zone is less than 7 spans, the number of peak amplitudes of the rail displacement is clearly consistent with the number of four wheelsets although the peak value increases gradually. As the length increases to 7 spans, the vibration effects caused by the front and rear wheelsets of the same bogie are gradually superimposed and the number of displacement amplitudes is almost merged to two, corresponding to the two bogies (front and rear bogies) with the length up to 10 spans. This indicates that the support stiffness under the rail has been greatly reduced. In Figure 11(b), the dominant frequencies of the acceleration in the states of contact loss are basically the same with the state of continuous contact focusing near $4 \mathrm{~Hz}, 8 \mathrm{~Hz}, 12 \mathrm{~Hz}$, $16 \mathrm{~Hz}, 20 \mathrm{~Hz}, 23 \mathrm{~Hz}, 28 \mathrm{~Hz}$, and $32 \mathrm{~Hz}$, while the amplitudes are clearly enlarged with the increase of the contact loss length. Comparing these conditions, it can be concluded that the contact loss between the concrete base and roadbed surface enlarges the vibration response of rail and the rail deflection increases significantly with the length of contact loss zone.

It can be seen in Figure 12(a) that the vibration effect caused by the front and rear wheelsets of the same bogie on the concrete base is clearly superimposed with only 2 


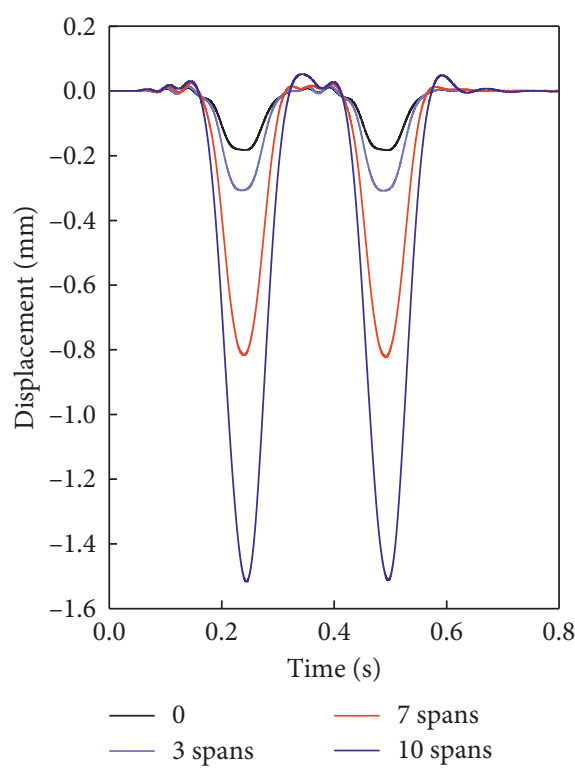

(a)

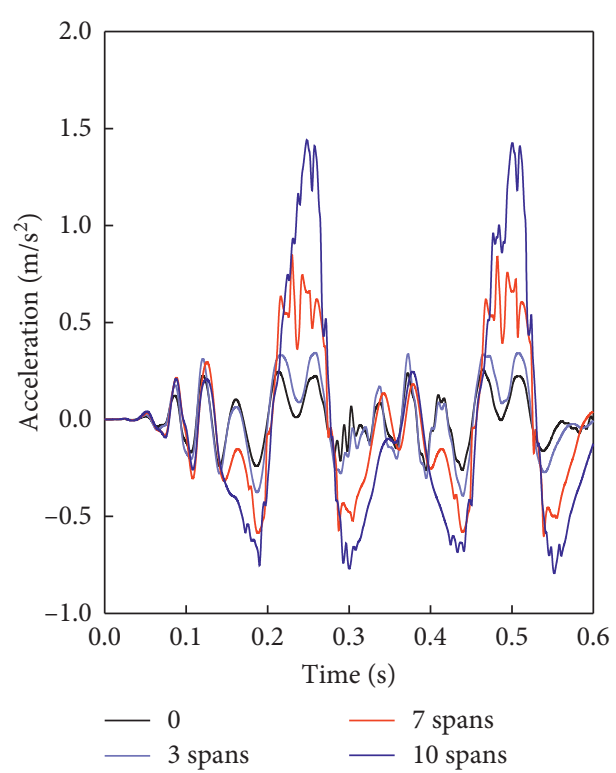

(b)

Figure 12: Dynamic displacement and acceleration of the concrete base with different lengths of contact loss zone: (a) dynamic displacement and (b) acceleration.

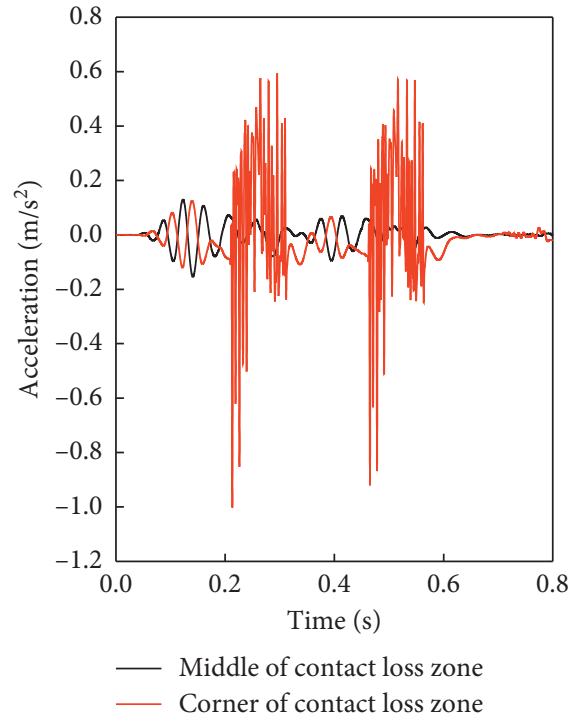

(a)

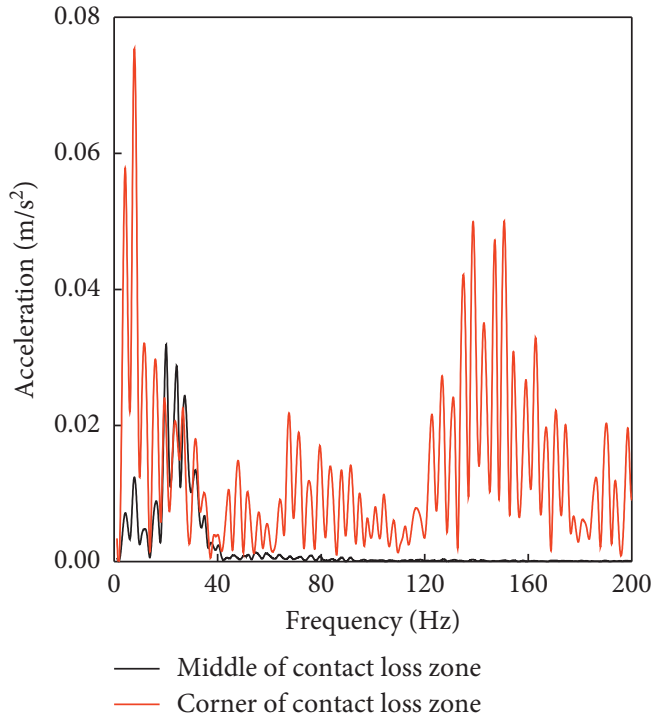

(b)

FIGURE 13: Time-frequency analysis of vibration acceleration at different positions of contact loss zone on the roadbed surface: (a) time domain and (b) frequency domain.

amplitudes corresponding to 2 bogies of a car and is amplified with the increase of the contact loss length. As the length of the contact loss zone exceeds 3 spans, the increment of the vertical dynamic displacement of the concrete base is great in the middle position of the contact loss zone. When the length reaches 10 spans, the peak value of the vertical displacement is $1.52 \mathrm{~mm}$, approximately 8 times of that in the normal condition. This shows that the support stiffness and constraint from the underlying roadbed is largely decreased. Meanwhile, the acceleration of the concrete base is increased simultaneously with the increase of contact loss length as depicted in Figure 12(b). When the length of contact loss zone is smaller than 7 spans, four amplitude values of the acceleration can be observed as four wheelsets pass through the contact loss area. When the length reaches 10 spans, the high vertical accelerations caused by the front and rear wheelsets of the same bogie are almost superimposed in the contact loss zone where only two peak amplitudes of the acceleration appear. 


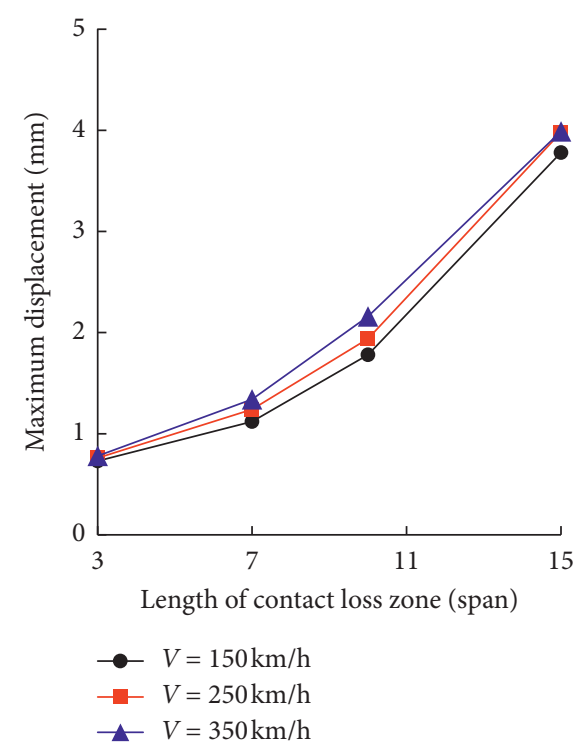

(a)

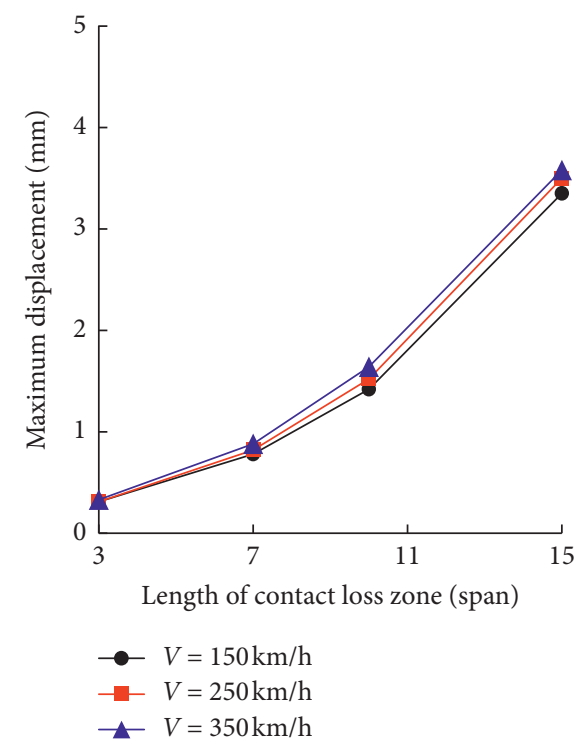

(c)

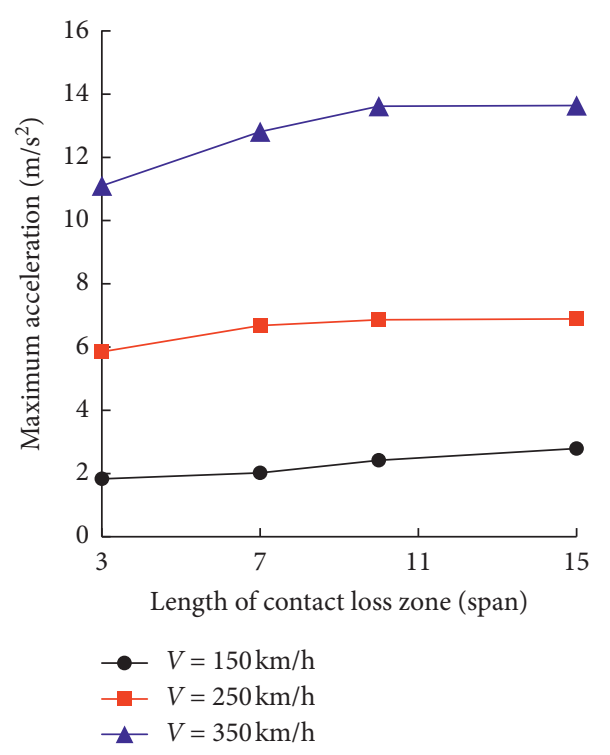

(b)

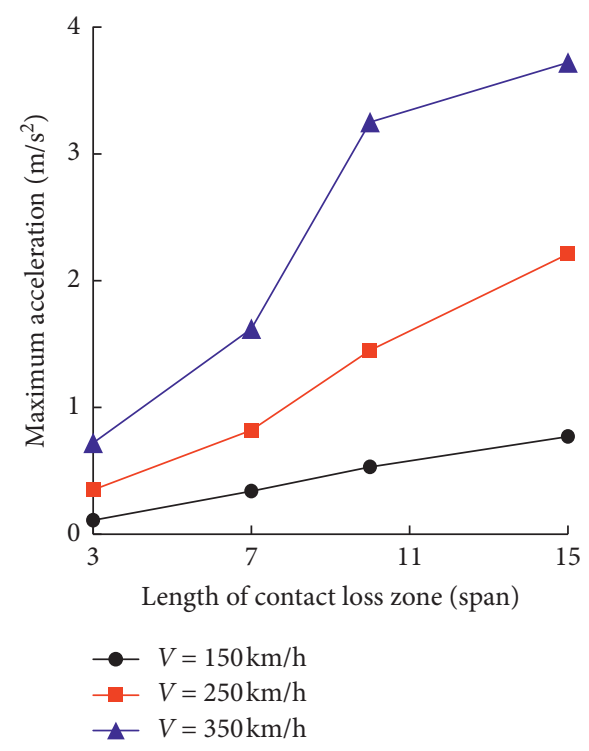

(d)

FIGURE 14: Vibration responses of track subsystem with different lengths of the contact loss zone and rail speeds: (a) dynamic displacement of rail, (b) acceleration of rail, (c) dynamic displacement of concrete base, and (d) acceleration of concrete base.

6.2. Vibration Responses of Roadbed Surface. Figure 13 shows the comparison of the accelerations between in the middle and at the corner of contact loss zone on roadbed surface for the case of 10-span-long and $1 \mathrm{~mm}$ deep contact loss area. For the middle of contact loss zone, the acceleration remains to be stably fluctuated because no stress interaction can be found due to the detachment of the concrete base and the roadbed surface. In contrast, a much higher vertical acceleration is mobilized at the corner of contact loss zone due to the stress concentration generated at this position as depicted in Figure 13(a). Similarly, in the middle of contact loss zone, the dominant frequency of vibration acceleration is approximately $7 \mathrm{~Hz}$ and $20 \mathrm{~Hz}$ while the dominant frequencies at the corner of contact loss zone are near $7 \mathrm{~Hz}$,
$48 \mathrm{~Hz}$, and $150 \mathrm{~Hz}$ with a much wider range (see Figure 13(b)). The transient impact resulting from an abrupt change from being contact to being loss at the corner of the contact likely induces high frequencies with the vibration amplitudes increased largely.

6.3. Index Analysis. Figure 14 presents the vibration responses of the rail and the concrete base with different lengths of the contact loss zones ( 3 spans, 7 spans, 10 spans, and 15 spans) and the rail speeds $(150 \mathrm{~km} / \mathrm{h}, 250 \mathrm{~km} / \mathrm{h}$, and $350 \mathrm{~km} / \mathrm{h}$ ) in the middle of contact loss zone. As can be seen from Figure 14(a), when the length of the contact loss zone is smaller than 10 spans, the vertical displacement peak amplitude of the rail has a relatively mild increase, while the 
length is greater than 10 spans, a sharp increase can be found, which even exceeded the limit $(2 \mathrm{~mm}$, required by Chinese technical regulations for dynamic acceptance for high-speed railways construction [35]) of the rail vertical displacement at the speed of $350 \mathrm{~km} / \mathrm{h}$. Also, the vertical displacement peak amplitude is not sensitive about the rail speed despite a general increase with the increase of rail speed. It can be seen in Figure 14(b) that the vertical acceleration of the rail tends to be stable after a slight increase within 10 spans of the contact loss length. With the same length, the rail speed has a significant effect on the rail acceleration. As shown in Figure 14(c), the vibration displacement peak amplitude of the concrete base shares the same trend as that of rail. Figure 14(d) shows that the vertical acceleration amplitude of the concrete base increases almost linearly with the length of contact loss at the rail speeds of $150 \mathrm{~km} / \mathrm{h}$ and $250 \mathrm{~km} / \mathrm{h}$, while at the rail speed of $350 \mathrm{~km} / \mathrm{h}$, the vertical acceleration increases steeply as the length of contact loss exceeds 7 spans. From the analysis above, it may be concluded that the vibration responses of the track system are greatly enlarged with the length of contact loss zone more than 10 spans, and this critical value may be considered as a threshold for treatment of the contact damage disease.

\section{Conclusions}

Based on the vehicle-track coupling dynamics theory and the theory of fluid dynamics in porous medium, a vertical vehicle-slab track-subgrade coupling vibration model capable of describing concrete base-roadbed surface contact variation under high-speed train load was developed. Dynamic data measured from a field case study were adopted for validating the computation model proposed. The influence of contact variation on the detailed dynamic responses of vehicle-track-subgrade system under different contact statuses is discussed. Following conclusions can be drawn based on the cases studied.

In the state of vibrating contact, the vibration responses of the concrete base and the roadbed surface were strongly enlarged by the transient impact and stress concentration induced from the concrete base-roadbed surface contact status changing from being detached to being interacted in comparison with the state of continuous contact. However, the vibrating contact-induced vibration responses of the vehicle and the rail were very limited due to the attenuation of damping from the CA mortar, the fasteners, and the primary and secondary suspension of a car body.

In the state of contact loss, the vibration responses of the key components (rail and concrete base) in the track system were remarkably increased with the increase of the contact loss length. For the roadbed surface, the stress concentration at the endpoint of the contact loss zone exerted greater influence on vibration responses than in the middle position. With the length of the contact loss zone more than 10 spans, the vertical displacement amplitude of the rail exceeded the standard value specified in the code of practice. In this case, it is inadvisable for the length of contact loss zone to exceed
10 spans for better structural durability and operation safety of the vehicle-track slab-subgrade system.

\section{Notations}

$M_{\mathrm{c}}: \quad$ Car body mass

$M_{\mathrm{t}}$ : Bogie mass

$M_{\mathrm{a}}$ : Axle mass

$M_{\text {wi }}$ : Mass of $i$ th wheel

$M_{\mathrm{r}}$ : Mass of rail beam

$J_{\mathrm{c}}: \quad$ Car rolling moment

$J_{\mathrm{t}}$ : Bogie rolling moment

$v_{\mathrm{c}}$ : Vertical displacement of car body

$v_{\mathrm{t} 1}$ : Vertical displacement of front bogie

$v_{\mathrm{t} 2}$ : Vertical displacement of rear bogie

$v_{\mathrm{w} i}$ : Vertical displacement of $i$ th wheel

$\varphi_{\mathrm{c}}$ : $\quad$ Pitch angle of car body

$\varphi_{1}$ : $\quad$ Pitch angle of front bogie

$\varphi_{2}$ : $\quad$ Pitch angle of rear bogie

$K_{\mathrm{s} 1}$ : Secondary suspension stiffness of front bogie

$K_{\mathrm{s} 2}$ : Secondary suspension stiffness of rear bogie

$K_{\mathrm{p}}$ : Primary suspension stiffness

$K_{\mathrm{h}}$ : Stiffness of wheel-rail contact

$k_{\mathrm{r}}$ : $\quad$ Rail pad stiffness

$k_{\mathrm{t}}$ : CA mortar stiffness

$C_{\mathrm{s} 1}$ : Secondary suspension damping of front bogie

$C_{\mathrm{s} 2}$ : Secondary suspension damping of rear bogie

$C_{\mathrm{p}}$ : Primary suspension damping

$l_{1}$ : Wheelbase

$l_{2}$ : Distance between bogie centers

$P$ : $\quad$ Axle load

$E_{\mathrm{r}} I_{\mathrm{r}}$ : Flexural stiffness of rail beam

$w_{\mathrm{r}}$ : Deflection of rail

$w_{s}$ : Deflection of concrete base

$w_{\mathrm{w}}$ : Wheel displacement

$E_{\mathrm{b}}$ : Elastic modulus of track slab

$c_{\mathrm{r}}$ : Rail pad damping

$F_{c}$ : Hertz contact force

$V: \quad$ Train's moving velocity

$\sigma_{i j, j}: \quad$ Stress tensor

$\sigma_{i j}^{\prime}: \quad$ Effective stress tensor

$u_{i}$ : Displacement vector

$c_{\mathrm{t}}: \quad$ CA mortar damping

$E$ : $\quad$ Elastic modulus

$E_{\mathrm{b}}$ : Elastic modulus of concrete base

$\delta_{i j}: \quad$ Kronecker delta

$\varepsilon_{i j}$ : Strain component

$\gamma_{\mathrm{w}}$ : Unit of pore water

$K_{\mathrm{f}}$ : $\quad$ Pore fluid bulk modulus

$\mu_{\mathrm{s}}, \lambda_{\mathrm{s}}$ : Constants

$v$ : Poisson's ratio

$\rho: \quad$ Density

$\rho_{\text {ss }}: \quad$ Solid density

$\rho_{\mathrm{b}}$ : Density of concrete base

$\rho_{1}: \quad$ Liquid density

$\rho_{\mathrm{f}}$ : $\quad$ Fluid density

$\rho_{s}: \quad$ Solid density

$p$ : $\quad$ Pore-water pressure 


\author{
n: $\quad$ Porosity \\ $\alpha$ : Compressibility parameter \\ $\eta$ : $\quad$ Fluid viscosity \\ k: $\quad$ Permeability.
}

\section{Data Availability}

The data used to support the findings of this study are available from the corresponding author upon request.

\section{Conflicts of Interest}

The authors declare no conflicts of interest regarding the publication of this paper.

\section{Acknowledgments}

The authors gratefully acknowledge the financial support of this work sponsored by the National Natural Science Foundation of China (grant nos. 51578467 and 51608461), the Technology Research and Development Program of Chinese Railway Corporation (grant no. 2016G002-E), and China University of Mining \& Technology (grant no. SKLGDUEK1726).

\section{References}

[1] C. Esveld, "Recent developments in slab track," European Railway Review, vol. 9, pp. 81-86, 2003.

[2] K. Liu, Q. Su, P. Ni, C. Zhou, W. Zhao, and F. Yue, "Evaluation on the dynamic performance of bridge approach backfilled with fibre reinforced lightweight concrete under high-speed train loading," Computers and Geotechnics, vol. 104, pp. 42-53, 2018.

[3] L. Li, S. Nimbalkar, and R. Zhong, "Finite element model of ballasted railway with infinite boundaries considering effects of moving train loads and Rayleigh waves," Soil Dynamics and Earthquake Engineering, vol. 114, pp. 147-153, 2018.

[4] C.-F. Zeng, G. Zheng, X.-L. Xue, and G.-X. Mei, "Combined recharge: a method to prevent ground settlement induced by redevelopment of recharge wells," Journal of Hydrology, vol. 568, pp. 1-11, 2019.

[5] D. Kostovasilis, D. J. Thompson, and M. F. M. Hussein, “A semi-analytical beam model for the vibration of railway tracks," Journal of Sound and Vibration, vol. 393, pp. 321-337, 2017.

[6] Z. Lei, L. Jiang, and W. Zhou, "An analytical study on dynamic response of multiple simply supported beam system subjected to moving loads," Shock and Vibration, vol. 2018, Article ID 2149251, 14 pages, 2018.

[7] W. Li, R. A. Dwight, and T. Zhang, "On the study of vibration of a supported railway rail using the semi-analytical finite element method," Journal of Sound and Vibration, vol. 345, pp. 121-145, 2015.

[8] W.-B. Wu, H. Liu, X. Yang et al., "New method to calculate the apparent phase velocity of open-ended pipe pile," Canadian Geotechnical Journal, 2019.

[9] X. Cui, Y. Wang, K. Liu et al., "A simplified model for evaluating the hardening behaviour of sensor-enabled geobelts during pullout tests," Geotextiles and Geomembranes, vol. 47, no. 3, pp. 377-388, 2019.

[10] M. Oregui, A. de Man, M. F. Woldekidan, Z. Li, and R. Dollevoet, "Obtaining railpad properties via dynamic mechanical analysis," Journal of Sound and Vibration, vol. 363, pp. 460-472, 2016.

[11] K. Wang, W. Zhai, K. Lv, and Z. Chen, "Numerical investigation on wheel-rail dynamic vibration excited by rail spalling in high-speed railway," Shock and Vibration, vol. 2016, Article ID 9108780, 11 pages, 2016.

[12] P. A. Costa, P. Lopes, and A. S. Cardoso, "Soil shakedown analysis of slab railway tracks: numerical approach and parametric study," Transportation Geotechnics, vol. 16, pp. 85-96, 2018.

[13] C. A. Ribeiro, R. Calçada, and R. Delgado, "Experimental assessment of the dynamic behaviour of the train-track system at a culvert transition zone," Engineering Structures, vol. 138, pp. 215-228, 2017.

[14] G. Lederman, S. Chen, J. Garrett, J. Kovačević, H. Y. Noh, and J. Bielak, "Track-monitoring from the dynamic response of an operational train," Mechanical Systems and Signal Processing, vol. 87, pp. 1-16, 2017.

[15] D. Chen, S. Han, C. Ling, and Q. Su, "Prediction of asphalt mixture surface texture level and its distributions using mixture design parameters," International Journal of Pavement Engineering, vol. 20, no. 5, pp. 557-565, 2019.

[16] L. Auersch, "Simultaneous measurements of the vehicle, track, and soil vibrations at a surface, bridge, and tunnel railway line," Shock and Vibration, vol. 2017, Article ID 1959286, 18 pages, 2017.

[17] B. Zhou, F. Zhang, and X. Xie, "Vibration characteristics of underground structure and surrounding soil underneath high speed railway based on field vibration tests," Shock and Vibration, vol. 2018, Article ID 3526952, 16 pages, 2018.

[18] T.-H. Liu, Z.-W. Chen, X.-D. Chen, T.-Z. Xie, and J. Zhang, "Transient loads and their influence on the dynamic responses of trains in a tunnel," Tunnelling and Underground Space Technology, vol. 66, pp. 121-133, 2017.

[19] J. Huang, Q. Su, W. Wang, X. Wang, and H. Guo, "Vibration behavior and reinforcement effect analysis of the slab tracksubgrade with mud pumping under cyclic dynamic loading: full-scale model tests," Shock and Vibration, vol. 2018, Article ID 3087254, 14 pages, 2018.

[20] Y. He, Y. Liu, H. Hazarika, and R. Yuan, "Stability analysis of seismic slopes with tensile strength cut-off," Computers and Geotechnics, vol. 112, pp. 245-256, 2019.

[21] G. Kouroussis, K. E. Vogiatzis, and D. P. Connolly, "A combined numerical/experimental prediction method for urban railway vibration," Soil Dynamics and Earthquake Engineering, vol. 97, pp. 377-386, 2017.

[22] D. Liu, Y.-F. Liu, J.-J. Ren, R.-S. Yang, and X.-Y. Liu, "Contact loss beneath track slab caused by deteriorated cement emulsified asphalt mortar: dynamic characteristics of vehicleslab track system and prototype experiment," Mathematical Problems in Engineering, vol. 2016, Article ID 3073784, 12 pages, 2016.

[23] W. Shi, "Study on effect of slab track structure defect on dynamic performance," M.S. thesis, Southwest Jiaotong University, Leshan, China, 2011.

[24] J. Xiang, D. He, and Q. Zeng, "Effect of cement asphalt mortar disease on dynamic performance of slab track," Journal of Central South University: Science and Technology, vol. 40, no. 3, pp. 791-796, 2009.

[25] J. Ren, X. Li, R. Yang, P. Wang, and P. Xie, "Criteria for repairing damages of CA mortar for prefabricated framework-type slab track," Construction and Building Materials, vol. 110, pp. 300-311, 2016. 
[26] Z. Chen, J.-L. Xiao, X.-K. Liu, X.-Y. Liu, R.-S. Yang, and J.-J. Ren, "Effects of initial up-warp deformation on the stability of the CRTS II slab track at high temperatures," Journal of Zhejiang University-Science A, vol. 19, no. 12, pp. 939-950, 2018.

[27] K. Liu, Q. Su, F. Yue, B. Liu, R. Qiu, and T. Liu, "Effects of suffosion-induced contact variation on dynamic responses of saturated roadbed considering hydro-mechanical coupling under high-speed train loading," Computers and Geotechnics, vol. 113, article 103095, 2019.

[28] W. Zhai, K. Wang, and C. Cai, "Fundamentals of vehicle-track coupled dynamics," Vehicle System Dynamics, vol. 47, no. 11, pp. 1349-1376, 2009.

[29] J. Sadeghi and M. Fesharaki, "Importance of nonlinearity of track support system in modeling of railway track dynamics," International Journal of Structural Stability and Dynamics, vol. 13, no. 1, article 1350008, 2013.

[30] X. Lei, High Speed Railway Track Dynamics: Model, Algorithm and Application, Science Press and Springer Nature Singapore Pte Ltd., Beijing, China, 2017.

[31] J. Blanco-Lorenzo, J. Santamaria, E. G. Vadillo, and O. Oyarzabal, "Dynamic comparison of different types of slab track and ballasted track using a flexible track model," Proceedings of the Institution of Mechanical Engineers, Part F: Journal of Rail and Rapid Transit, vol. 225, no. 6, pp. 574-592, 2011.

[32] J. Huang, Q. Su, T. Liu, and W. Wang, "Behavior and control of the ballastless track-subgrade vibration induced by highspeed trains moving on the subgrade bed with mud pumping," Shock and Vibration, vol. 2019, Article ID 9838952, 14 pages, 2019.

[33] O. C. Zienkiewicz and T. Shiomi, "Dynamic behaviour of saturated porous media; the generalized Biot formulation and its numerical solution," International Journal for Numerical and Analytical Methods in Geomechanics, vol. 8, no. 1, pp. 71-96, 1984.

[34] W. Zhang, Q. Su, T. Liu, and W. Sun, "Research on vibration characteristics of ballastless track subgrade under frost boiling at subgrade bed," Rock and Soil Mechanics, vol. 35, no. 12, pp. 3556-3568, 2014.

[35] Ministry of Railways of China, Chinese Technical Regulations for Dynamic Acceptance for High-Speed Railways Construction, China Railway Press, Beijing, China, TB 10761-2013, 2013. 


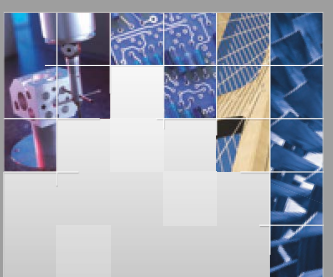

\section{Enfincering}
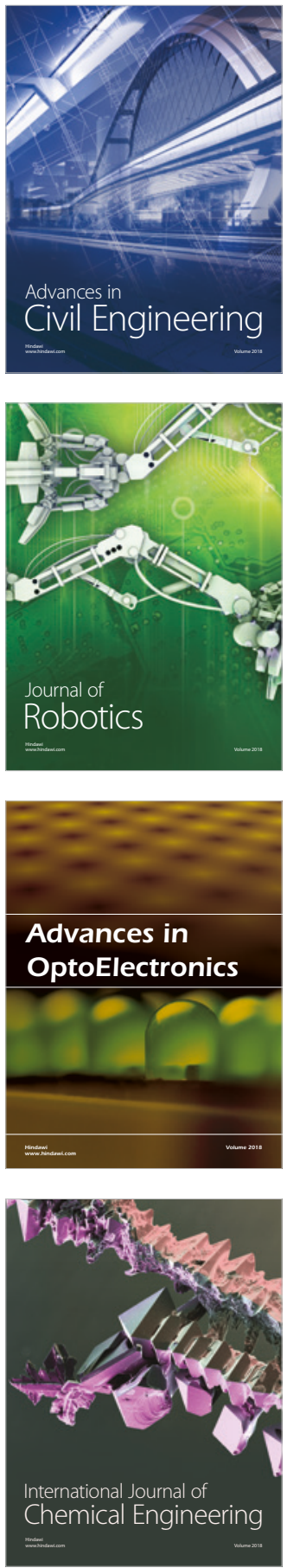

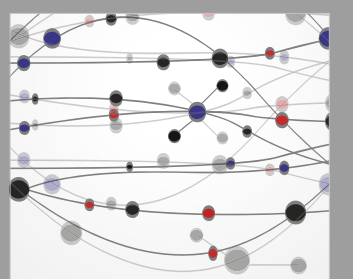

\section{Rotating \\ Machinery}

The Scientific World Journal

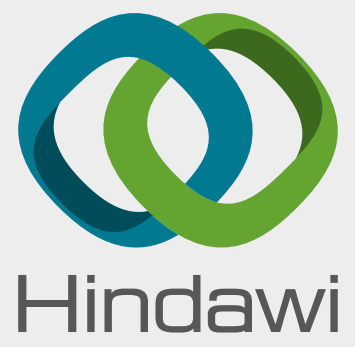

Submit your manuscripts at

www.hindawi.com
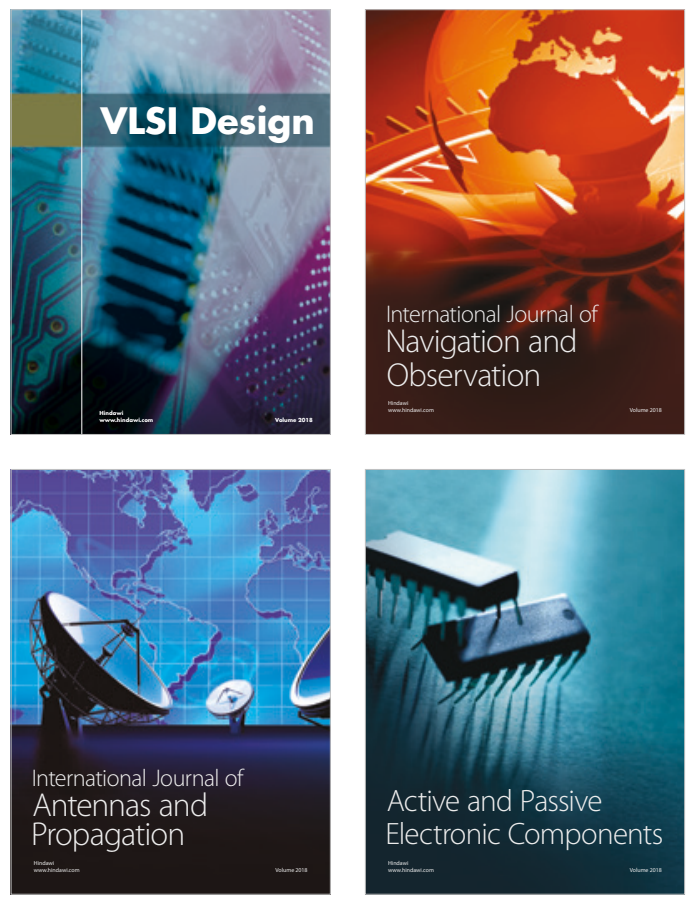
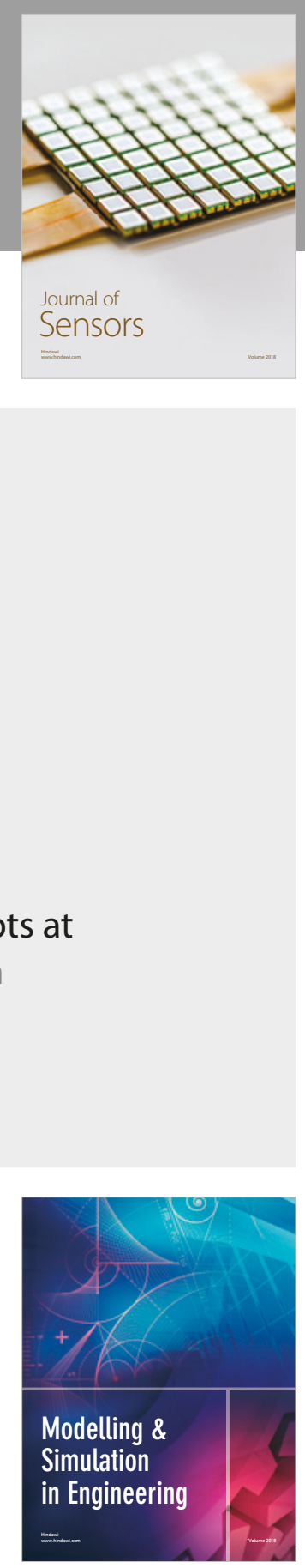

\section{Advances \\ Multimedia}
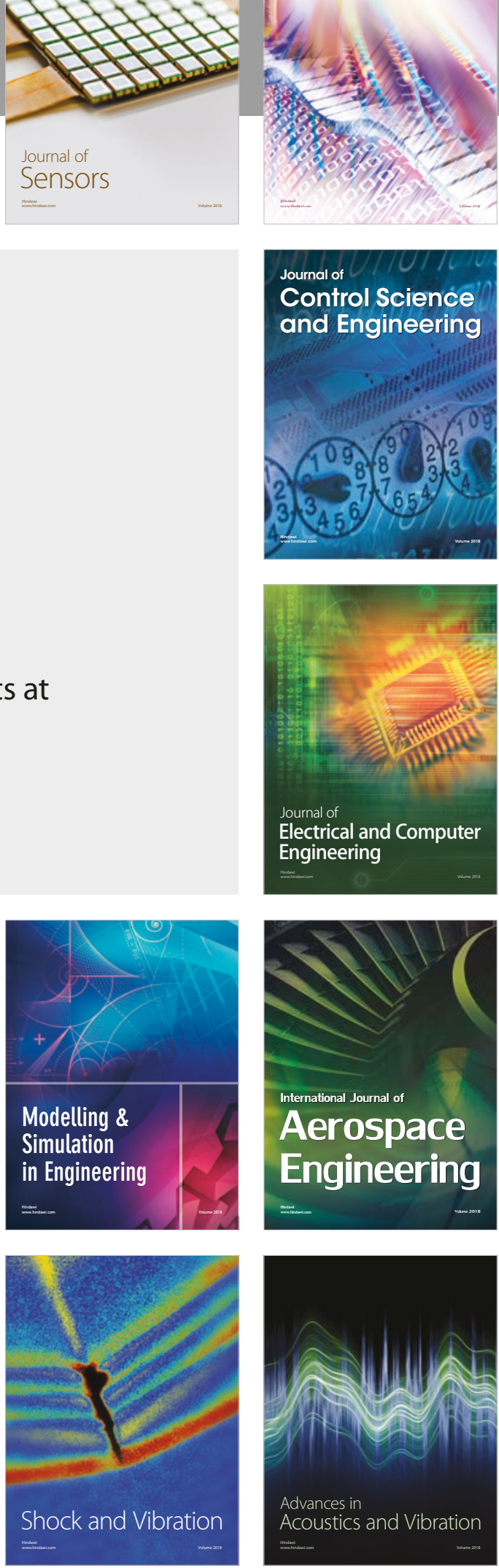